(c) Elsevier/INRA

Original article

\title{
Phenotypic and genetic variability of morphometrical traits in natural populations of Drosophila melanogaster and $D$ simulans. II. Within-population variability
}

\author{
P Capy, E Pla, JR David \\ Centre National de la Recherche Scientifique, Laboratoire de Biologie \\ et Génétique Evolutives, 91198 Gif-sur-Yvette Cedex, France
}

(Received 30 March 1993; accepted 10 August 1993)

\begin{abstract}
Summary - Within-population variability was investigated in the 2 sibling species Drosophila melanogaster and $D$ simulans at both phenotypic and genetic levels. Six quantitative traits were studied in 55 different populations of $D$ melanogaster and 25 populations of $D$ simulans encompassing most of the cosmopolitan range of the 2 species. The phenotypic variabilities of all the traits were compared using the coefficients of variation $(C V)$. Differences among $C V$ 's were broader than expected from their theoretical sampling distribution. Temperate populations were generally less variable than tropical ones. Moreover, in both species, the $C V$ of the 3 size-related traits (fresh weight, wing length and thorax length) were correlated. Comparison of the 2 species showed that the average variabilities (mean values of $C V$ ) were almost identical with the exception of ovariole number which is much less variable in $D$ simulans $(6 \%$ against $8 \%)$. At the genetic level, distributions of intraclass correlations did not show any departure from the expected sampling distributions, suggesting that all populations harbored a similar amount of genetic variability. For most traits, no significant difference was found between the 2 species, except again for the ovariole number which is genetically less variable in $D$ simulans. An overall analysis of the total variability showed that $78 \%$ of the total variance was explained by the within-population components in $D$ simulans against $50 \%$ in $D$ melanogaster.
\end{abstract}

Drosophila melanogaster / Drosophila simulans / morphological traits / withinpopulation variability / isofemale lines

Résumé - Variabilité phénotypique et génétique de caractères morphologiques dans les populations naturelles de Drosophila melanogaster et Drosophila simulans. II. Variabilité intrapopulation. La variabilité intrapopulation a été analysée dans les populations naturelles de 2 espèces jumelles, Drosophila melanogaster et D simulans. Six caractères morphologiques ont été mesurés dans 55 populations de $\mathrm{D}$ melanogaster et 25 populations de $\mathrm{D}$ simulans couvrant la plupart des régions où ces 2 espèces existent. Au niveau 
phénotypique, on a observé chez les 2 espèces et pour tous les caractères que la variabilité de la distribution des coefficients de variation (CV) était supérieure à la variabilité attendue dans le cas d'un échantillonnage au hasard. Cela met en évidence que des populations sont beaucoup plus variables que d'autres. Ainsi, les populations tempérées sont moins variables que les populations tropicales. Par ailleurs, les CV de 3 caractères (le poids frais, les longueurs de l'aile et du thorax) sont positivement corrélés. La comparaison des 2 espèces sur la base des moyennes des distributions des $C V$ ne permet pas de mettre en évidence de différences significatives, à l'exception du nombre d'ovarioles, qui est moins variable chez $\mathrm{D}$ simulans. Au niveau génétique, les distributions observées de la corrélation intraclasse sont conformes aux distributions théoriques attendues. À l'exception du nombre d'ovarioles qui s'avère une nouvelle fois moins variable chez $\mathrm{D}$ simulans, il n'existe pas, pour les autres caractères, de différences significatives entre les moyennes des distributions de ce paramètre chez les 2 espèces. Ainsi, pour la majeure partie des caractères analysés au cours de ce travail, les 2 espèces présentent des niveaux de variabilité comparables. $L$ 'analyse globale de la variabilité des 2 espèces montre que $78 \%$ de la variance totale de $\mathrm{D}$ simulans est observée au niveau intrapopulation, contre $50 \%$ chez $\mathrm{D}$ melanogaster.

Drosophila melanogaster / Drosophila simulans / caractères morphologiques / variabilité intrapopulation / lignées isofemelles

\section{INTRODUCTION}

Although it is generally assumed that phenotypic traits are the primary target of natural selection (Lewontin, 1974), analysis of such characters has been somewhat neglected in favor of molecular variations and most analyses have been devoted to laboratory rather than to natural populations.

In this respect, Drosophila melanogaster has been used as a model organism for quantitative genetics and a huge amount of data has been accumulated. Numerous investigations have dealt with selection experiments (see Roff and Mousseau, 1987, for a review) and tried to locate genes with major effects (Thoday, 1961; Thompson, 1975; Shrimpton and Robertson, 1988).

By comparison, the analysis of the morphological variability of natural populations has remained less developed. Such variations were investigated in several species such as $D$ robusta, $D$ subobscura, $D$ persimilis and $D$ pseudoobscura, $D$ melanogaster and $D$ simulans (see David et al, 1983, for a review). But in all cases, the main interest was focused more on the geographic variability of the mean values of various traits (between-population variability) than on the withinpopulation variability. One possible reason for which the genetic architecture of natural populations has remained less investigated is that quantitative genetic techniques need a large amount of data if the heritability is to be estimated with precision. So, with a few exceptions (Suh and Mukai, 1991, and references therein) the possibility that genetic variability could vary according to some geographic trend has not been considered.

During the last decade, we have progressively investigated numerous natural populations of Drosophila from various parts of the world, studying 6 quantitative traits by the isofemale line technique. Such a technique allows one to estimate both phenotypic and genetic variabilities. This analysis concerns $D$ melanogaster 
for which 55 different populations were available, and its sibling species $D$ simulans, which also exhibits a cosmopolitan distribution and for which 25 populations have been studied. These 2 sets of populations were used to compare the phenotypic and genetic variabilities within natural populations of the 2 sibling species. The interest of such a comparative approach arises from the fact that these 2 cosmopolitan species are sympatric in most parts of the world, show similar seasonal demographic profiles (David et al, 1983) and are probably exposed to similar environmental pressures. From analyses of other traits (see discussion of Capy et al, 1993), it seems that ecological success and colonization ability of these 2 species are based on different genetic strategies (Singh et al, 1987). Therefore, in such a context, it is important to analyze their phenotypic and genetic variability for various kinds of traits, in order to determine whether they share similar genetic architectures.

In this work, we have found that the 2 species exhibit similar levels of phenotypic and genetic variability for most of the traits considered here. The main exception concerns the ovariole number for which $D$ melanogaster is much more variable than $D$ simulans both phenotypically and genetically. Our results will be discussed according to what is known for these 2 species for other traits. Finally, the apportionment of the total variability in these 2 species, from the within-population component to the variability between geographical regions, will also be discussed.

\section{MATERIALS AND METHODS}

\section{Natural populations and morphological traits}

The natural populations morphological traits here studied and the techniques used (isofemale lines) have already been described in the previous paper (Capy et al, 1993).

\section{Estimation of variability}

The variability of each natural population was estimated by using the coefficient of variation for the phenotypic variability $(C V)$ and the intraclass correlation $(t)$, calculated from an analysis of variance. This latter parameter is related to the genetic variability (Falconer, 1981) and can be assimilated to an isofemale line heritability (Parsons, 1983).

Comparison of phenotypic variability of the different populations was performed using Levene's test for homogeneity of variances (Levene, 1960). Variates of each population were transformed according to the following formula:

$$
Y_{i j k}^{\prime}=\mid \operatorname{Ln} Y_{i j k}-\overline{\operatorname{Ln} Y_{i j}}
$$

where $\overline{Y_{i j k}}$ is the value of individual $k$, for the variate $j$ in the population $i$ and where $\operatorname{Ln} Y_{i j}$. is the mean of the logarithm of the population $i$. To test whether the average absolute deviations were identical for the different populations, a single one-way analysis of variance was performed.

The distributions of the intraclass correlations were also analyzed. To test the homogeneity of this coefficient among the studied populations, the observed and 
theoretical distributions were compared by a Kolmogorov-Smirnov test assuming that the ratio:

$$
\frac{1-t}{1+(n-1) t} \times \frac{M_{1}}{M_{2}}
$$

follows an $F$ distribution with $N-1, N(n-1)$ degrees of freedom (Bulmer, 1985). In this expression, $M_{1}$ and $M_{2}$ are the observed mean squares between and within isofemale lines. Theoretical density functions and probabilities were calculated using the approximation of Jaspen (1965).

Comparisons between $D$ melanogaster and $D$ simulans were performed assuming that the variables are normally distributed. Therefore, classical tests such as Student's test for comparisons of means and Fisher-Snedecor test for comparisons of variances, were used. The comparisons were also made by using non-parametric methods like the Mann-Whitney $U$ test or Spearman rank correlation. Whatever the method used, the conclusions of the test were identical.

\section{RESULTS}

\section{Phenotypic variability}

Basic data, ie mean values and standard errors of each trait, were given in table I of Capy et al (1993). As previously indicated, significant variations exist between means of the different populations according to their geographic origin. When several distributions have different means, a positive correlation between mean and variance is generally expected, due to a scaling effect. From the present data, only one correlation between means and variances (ie for the sternopleural bristle number in $D$ melanogaster) was significantly positive, and 5 correlations among 12 were negative (not shown). Thus, in both species, there is no clear evidence that higher means imply higher variance. However, variability has also to be compared between species. For most traits, mean values of $D$ simulans are smaller than those of $D$ melanogaster (Capy et al, 1993). For this reason a relative measurement of variability, $i e$ the coefficient of variation, $C V$, has been used throughout this paper. Moreover, the $C V$ allows the comparison of variabilities of different traits expressed with different metrics, such as wing length and ovariole number.

Because of space shortage, a table with the $C V \mathrm{~s}$ of the various traits in each population is not given. But, for all traits, the lowest $C V$ is, in general, 2- to 4-fold less that the highest $C V$. Moreover, it is often observed that a given population may be highly variable for some traits while not for others. For example, in $D$ melanogaster, the Ottawa population (Canada), which was the most variable for fresh weight, was among the least variable for thoracic length. The same phenomenon could be observed for $D$ simulans (Seville population, Spain). For this species, it may also be stressed that the Bizerte population (Tunisia) was among the least variable for 3 of the 6 traits: FW, TL and WL.

Means and variances of the distributions of the $C V \mathrm{~s}$ are given in table I for the 6 morphological traits. In each species, there is no significant difference between mean values of $C V \mathrm{~s}$ or between their variances when the total samples 
Table I. Means and variances of the coefficients of variation of various traits in $D$ melanogaster and $D$ simulans. Comparisons are based on sympatric populations (21 populations).

\begin{tabular}{|c|c|c|c|c|c|c|c|}
\hline \multirow[t]{2}{*}{ Traits } & & \multicolumn{2}{|c|}{ D melanogaster } & \multicolumn{2}{|c|}{ D simulans } & \multirow[b]{2}{*}{ Comparison } & \multirow[b]{2}{*}{$\mathrm{r}$} \\
\hline & & $\mathrm{n}=55$ & $\mathrm{n}=21$ & $\mathrm{n}=25$ & $\mathrm{n}=21$ & & \\
\hline \multirow[t]{2}{*}{ Fresh weight } & Mean & 5.47 & 5.21 & 5.44 & 5.31 & $t=0.23$ & $0.45^{*}$ \\
\hline & Variance & 3.65 & 2.72 & 2.20 & 1.62 & $F=1.68$ & \\
\hline \multirow[t]{2}{*}{ Thorax length } & Mean & 3.14 & 2.45 & 3.28 & 2.51 & $t=0.68$ & -0.13 \\
\hline & Variance & 0.55 & 0.63 & 0.25 & 0.27 & $F=2.34^{*}$ & \\
\hline \multirow[t]{2}{*}{ Wing length } & Mean & 2.46 & 2.45 & 2.49 & 2.51 & $t=0.51$ & 0.40 \\
\hline & Variance & 0.29 & 0.15 & 0.11 & 0.10 & $F=1.48$ & \\
\hline \multirow[t]{2}{*}{ Abdominal bristles } & Mean & 8.91 & 9.03 & 9.37 & 9.47 & $t=1.42$ & -0.10 \\
\hline & Variance & 1.28 & 1.02 & 1.22 & 0.99 & $F=1.03$ & \\
\hline \multirow[t]{2}{*}{ Sternopleural bristles } & Mean & 11.04 & 11.33 & 10.54 & 10.47 & $t=1.99$ & -0.32 \\
\hline & Variance & 2.04 & 2.67 & 2.12 & 1.28 & $F=2.09$ & \\
\hline \multirow[t]{2}{*}{ Ovariole number } & Mean & 8.06 & 7.60 & 6.21 & 6.20 & $t=2.97^{* *}$ & 0.19 \\
\hline & Variance & 5.20 & 3.35 & 1.15 & 1.31 & $F=2.56^{*}$ & \\
\hline
\end{tabular}

Level of significance: ${ }^{*}<5 \%,{ }^{* *}<1 \% ; t=$ comparison of means (Student's test, $d f=40$ ); $F=$ comparison of variance $(F$-test, $d f=20,20) ; r=$ correlation between $C V$ of the 2 species $(d f=19)$; non-parametric tests gave similar conclusions.

or the 21 sympatric populations are considered. Therefore, for each species, these 21 populations are a convenient sample of the overall populations.

The comparison of the 2 species shows a clear difference for the ovariole number which is less variable in $D$ simulans than in $D$ melanogaster (average $C V$ s are 6.2 and 7.6). The same conclusion arises when all populations of the 2 species are considered. For the other traits, the mean $C V \mathrm{~s}$ of the 2 species are not different. If we then compare the variances of the $C V$ distributions, we find that they are always greater in $D$ melanogaster, but significantly so in only 2 cases'(ON and TL). Finally, correlations between $C V \mathrm{~s}$ of the 2 species are generally not significant, except for fresh weight, suggesting that there are no parallel variations of the phenotypic variability between $D$ melanogaster and $D$ simulans for the other traits.

Levene's tests for homogeneity of variances (not given) show that, for all traits, a significant population effect exists or, in other words, that within-population variances are heterogeneous. Another method proposed by Brotherstone and Hill (1986), based on the comparison between the observed and the theoretical distributions of the standard deviations or of the coefficients of variation, provided similar results.

The intra-specific correlations between the $C V \mathrm{~s}$ of the different traits are given in table II. Although most of these correlations are not significant, there is an average tendency toward positive values $(21 / 30)$. Three of them, concerning the 3 traits related to size, are significantly positive in both species. This result is not unexpected since the mean values of these traits are themselves positively correlated. On the other hand, the positive correlation found in $D$ melanogaster between fresh weight variability (measured in males) and female ovariole number variability could be more interesting from a biological point of view. 
Table II. Correlations between the coefficients of variation of the 6 morphological traits in $D$ melanogaster (above diagonal, $n=55$ ) and $D$ simulans (below diagonal, $n=25$ ).

\begin{tabular}{lcccccc}
\hline Traits & $F W$ & $T L$ & $W L$ & $A B$ & $S B$ & $O V$ \\
\hline Fresh weight & & $0.284^{*}$ & $0.397^{* *}$ & $0.288^{*}$ & -0.071 & $0.469^{* *}$ \\
Thorax length & $0.454^{*}$ & & $0.437^{* *}$ & 0.153 & -0.247 & 0.220 \\
Wing length & $0.422^{*}$ & $0.426^{*}$ & & 0.216 & -0.132 & 0.134 \\
Abdominal bristles & 0.209 & 0.325 & 0.264 & & -0.095 & 0.184 \\
Sternopleural bristles & -0.042 & 0.271 & 0.003 & 0.244 & & 0.193 \\
Ovariole number & 0.016 & -0.266 & -0.033 & -0.084 & -0.020 & \\
\hline
\end{tabular}

Level of significance: ${ }^{*}<5 \% ;^{* *}<1 \%$.

Phenotypic variability was also analyzed according to the geographic origin of the populations (table III). In $D$ melanogaster, for which more populations are available, 3 traits (FW, AB and TL) exhibit a significant negative correlation with latitude of origin. Populations living at higher latitudes are less variable than tropical ones. When geographic groups are considered, 3 traits (SB, TL and ON) show a significant between-group heterogeneity. Interestingly, for 2 of them no significant correlation was found with latitude.

Table III. Relationship between phenotypic variability $(C V)$ and latitude or region of origin.

\begin{tabular}{|c|c|c|c|c|}
\hline & \multicolumn{2}{|c|}{ D melanogaster } & \multicolumn{2}{|c|}{ D simulans } \\
\hline & $\underset{\mathrm{r}}{\text { Latitude }}$ & $\underset{\text { Region }}{\mathrm{F}}$ & $\stackrel{\mathrm{r}}{\text { Latitude }}$ & $\begin{array}{c}\mathbf{F} \\
\text { Region }\end{array}$ \\
\hline Fresh weight & $-0.284^{*}$ & 2.15 & -0.117 & 0.60 \\
\hline Thorax length & $-0.495^{* *}$ & $3.89^{* *}$ & -0.059 & 1.05 \\
\hline Wing length & -0.175 & 0.43 & 0.106 & 2.10 \\
\hline Abdominal bristles & $-0.326^{* *}$ & 1.42 & 0.174 & 0.63 \\
\hline Sternopleural bristles & 0.131 & $3.15^{* *}$ & -0.042 & 0.50 \\
\hline Ovariole number & -0.118 & $2.31^{*}$ & -0.174 & 1.19 \\
\hline
\end{tabular}

Level of significance: ${ }^{*}<5 \% ;{ }^{* *}<1 \% ; r=$ coefficient of correlation; $F=$ result of an ANOVA testing the region effect. This analysis was performed on the natural populations clustered according to their geographical origin. For $D$ melanogaster 10 groups were considered and 6 for $D$ simulans. Geographical groups for $D$ melanogaster: France, USSR, North Africa, Tropical Africa, Islands of Indian Ocean close to the African continent, South Africa, North America, West Indies and Mexico, Far East and Australia Geographical groups for $D$ simulans: France, North Africa, Tropical Africa, South Africa, French West Indies, Mexico and USA, Islands of Indian Ocean close to the African continent.

On the whole, we find that $D$ melanogaster exhibits a significant geographic differentiation not only for the mean values of the traits but also for their variability. In $D$ simulans none of these analyses showed any significant geographical differentiation suggesting a higher homogeneity between populations. 


\section{Genetic variability}

The total variance of each population may be partitioned into 2 components: variance within and variance between isofemale lines. A one-way analysis of variance gives the mean squares within and between families, and from the expectations of these mean squares, it is possible to estimate the intraclass correlation $t$. Assuming that epistatic interactions, common environmental effects, and the dominance variance are small compared with the additive genetic variance, $t$ estimates half the narrow sense heritability (Falconer, 1981; Capy, 1987) or estimates the isofemale heritability according to Parsons (1983) and Hoffmann and Parsons (1988).

Means and standard deviations of intraclass correlations are given in table IV. In both species, the observed and theoretical distributions are identical (not shown) and none of the comparisons using a Kolmogorov-Smirnov test are significant, leading to the conclusion that there is no genetic heterogeneity between populations. Significant differences exist between intraclass correlations ( $i e$ isofemale heritability) of the various traits. In both species, the highest heritabilities are observed for traits related to size, ie fresh weight and wing length with values ranging between 0.40 and 0.53 . We then find the bristle numbers (range 0.21 and 0.32 ). Although thorax length is related to size, it is less variable ( 0.18 and 0.23 in the 2 species). Ovariole number also exhibits a fairly low genetic variability $(0.25$ and 0.14$)$.

When the 2 species are compared, 2 significant differences are found, for sternopleural bristles and ovariole numbers. For both traits, $D$ simulans is less variable. On the other hand, when the $t$ values of the sympatric populations of the 2 species are considered, none of the coefficients of correlation is significant. Thus, living in the same area does not lead to similar intrapopulation genetic variations.

Correlations between $t$ values of different traits are given in table V. As previously observed for the coefficient of variation, only correlations involving FW, TL and WL are significant in $D$ melanogaster. Although these correlations do not correspond to genetic correlations, such a result suggests that these traits, which are related to size, either share a common genetic basis or are submitted to similar internal constraints or are under similar external selective pressures. In $D$ simulans, only the correlation between FW and WL is significant while the thorax length seems to be independent of these 2 traits. Therefore, it is possible that this difference between the 2 species reflects some differences in the genetic structure of these traits. For example, some pleiotropic effects could exist in $D$ melanogaster but not in $D$ simulans.

The analysis of the geographical distribution of intraclass correlations does not show any latitudinal variations and region effects, with an exception for the abdominal bristle number in $D$ simulans. Therefore, all regions exhibit a similar level of genetic variability for most of the traits considered here, in spite of the geographical variability of the mean values of the traits, and also of the total phenotypic variance. 


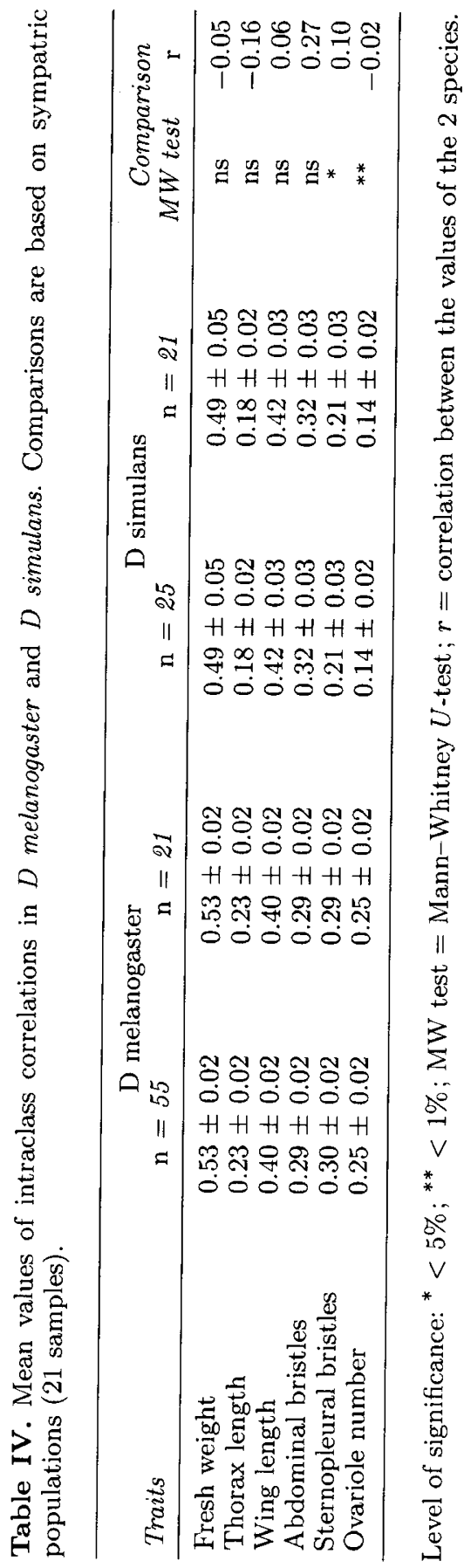


Table V. Correlations between the intraclass correlations of the 6 morphological traits in $D$ melanogaster (above diagonal, $n=55$ ) and $D$ simulans (below diagonal, $n=25$ ). Similar results were obtained with the Spearman rank correlation (not shown).

\begin{tabular}{lcccrrr}
\hline Traits & $F W$ & $T L$ & $W L$ & \multicolumn{1}{c}{$A B$} & \multicolumn{1}{c}{$S B$} & \multicolumn{1}{c}{$O V$} \\
\hline Fresh weight & & $0.251^{*}$ & $0.301^{*}$ & -0.025 & -0.193 & 0.201 \\
Thorax length & 0.071 & & $0.306^{*}$ & -0.060 & 0.214 & 0.066 \\
Wing length & $0.449^{*}$ & 0.010 & & 0.082 & 0.134 & 0.126 \\
Adominal bristles & 0.125 & 0.385 & 0.019 & & -0.071 & -0.116 \\
Sternopleural bristles & -0.222 & 0.370 & -0.124 & 0.345 & & 0.139 \\
Ovariole number & -0.132 & 0.101 & 0.326 & -0.210 & -0.090 & \\
\hline
\end{tabular}

Level of significance: ${ }^{*}<5 \%$.

\section{DISCUSSION AND CONCLUSIONS}

Our analysis of the within-population variability of the 2 sibling species shows that for most of the traits considered here, the 2 species exhibit similar levels of variability. The main exception concerns the ovariole number for which $D$ melanogaster is phenotypically and genetically more variable than $D$ simulans. The large amount of biometrical data presented in this paper will be discussed in several ways.

\section{Phenotypic variance and coefficients of variation}

It is well known (David et al, 1980) that wild living Drosophila adults are submitted to variable environments during their development, resulting in a broad phenotypic variance in natural populations. For genetic purposes, we need to control growth conditions and reduce the environmental component (David, 1979). The coefficients of variation measured in the laboratory are often 2 or 3 times less than in nature. Our results show that significant differences in $C V$ values exist between different traits in the 2 species. Size-related traits are the least variable (from 2.5 to $5.5 \%$ ) while bristle numbers are most variable (from 8.9 to $11.0 \%$ ). A classical interpretation (Lerner, 1954) is that traits related to fitness are submitted to a permanent selection and developmental canalization, thus resulting in a low variability. Our results are in agreement with this general expectation: size is certainly related to fitness, while for bristle numbers, the relationship is dubious. Ovariole number is known to be related to egg production, at least under laboratory conditions (Bouletreau-Merle et al, 1982) and is thus a clear component of fitness. However this trait exhibits a large variability between individuals, since in $D$ melanogaster the average $C V$ is $8 \%$. A possibility could be that the ovariole number in nature is less related to fecundity than in the laboratory. In $D$ simulans, the variability is much less $(6.2 \%)$. Maybe in this species, a stronger relationship exists between ovarian size and egg production.

An interesting result is the heterogeneity of the $C V \mathrm{~s}$ between populations. Such a result was previously found by comparing laboratory mass cultures (David et $a l, 1978$ ) but in that case, no interpretation was provided, since the reduction of variance in laboratory strains could be due to genetic drift. In this paper, the drift 
hypothesis can be excluded: different natural populations really exhibit different levels of phenotypic variance. The conclusion is enforced by the fact that most $C V \mathrm{~s}$, at least in $D$ melanogaster, exhibit significant geographic patterns and especially a negative correlation with latitude. In this case, a biological interpretation can be proposed. This could be related to the average population size which is likely to be higher in the tropics than in temperate countries with a winter bottleneck.

\section{Intraclass correlation and heritability}

With the isofemale-line technique, the genetic variability within a natural population is approached by calculating the coefficient of intraclass correlation $t$. In most works using this technique (see Parsons, 1983, for references), investigators are satisfied with demonstrating a genetic component of the trait under study. This work presents a large amount of comparative data, which makes a deeper analysis possible.

A first interesting conclusion is the apparent homogeneity of the intraclass correlations in natural populations. The variations observed are mainly due to sampling errors and especially to the fact that, in most cases, only 10 isofemale lines were considered in each population. Such a result contrasts with the geographic differences observed at the level of phenotypic variances. In practice, the withinand between-line variances are correlated in each population, thus explaining the lower variability of $t$ as compared to $C V$.

A second observation concerns the differences between the average values of $t$ for various traits. In this respect the most genetically variable trait is the fresh weight (about 0.50) followed by wing length (about 0.40). Bristle numbers are less variable (range $0.21-0.32$ ). Thorax length also exhibits a low variability $(0.18-0.23$ ), significantly much less than wing length. Finally, the ovariole number also has a low heritability (isofemale heritability), especially in $D$ simulans which is genetically less variable than its sibling.

A final interesting point is the possible relationship between isofemale heritability and usual heritability (narrow sense heritability). In the case of $D$ melanogaster, numerous experimental data are available and were compiled by Roff and Mousseau (1987). The results are compared in table VI, and also include a wing length analysis in $D$ simulans.

True heritability estimates are much higher for bristle numbers that for wing or thorax length. This makes sense, according to Fisher (1930), if we assume that bristle numbers are more or less neutral, while thorax and wing length are more directly related to fitness. We already pointed out that, under some simplifying assumptions (Falconer, 1981), 2t should be equal to $h^{2}$. The ratios indicated in table VI never reach such a value. We see however that for bristle numbers, a value close to 1.5 is found. Also for the thorax length, $t$ is clearly less than $h^{2}$. These observations suggest that for these traits, genetic variations in natural populations are mainly due to additive effects. Wing length in both species shows a completely different picture since $t$ is consistently higher than $h^{2}$. We may assume that the genetic architecture of wing length in natural populations is quite different from that of thorax length, with a predominance of non-additive effects due to dominance and epistasis. Further investigations should consider this point. 
Table VI. Comparison of the intraclass correlation (present study) with previous estimations of narrow sense heritability using various techniques. Heritability data are from a compilation by Roff and Mousseau (1987).

\begin{tabular}{lccccc}
\hline Species and traits & $\begin{array}{c}\text { Intraclass correlation } \\
\mathrm{m} \pm \text { se }\end{array}$ & $\begin{array}{c}\text { Heritability } \\
\mathrm{m} \pm \text { se }\end{array}$ & $\mathrm{n}$ & MW test & $\mathrm{R}$ \\
\hline D melanogaster & & & & & \\
Abdominal bristles & $0.292 \pm 0.018$ & $0.415 \pm 0.026$ & 43 & $* *$ & 1.42 \\
Sternopleural bristles & $0.295 \pm 0.017$ & $0.436 \pm 0.014$ & 87 & $* *$ & 1.48 \\
Thorax length & $0.232 \pm 0.019$ & $0.319 \pm 0.021$ & 30 & $* *$ & 1.38 \\
Wing length & $0.403 \pm 0.021$ & $0.325 \pm 0.014$ & 66 & $* *$ & 0.81 \\
$D$ simulans & & & & & \\
Wing length & $0.416 \pm 0.034$ & $0.297 \pm 0.012$ & 24 & $* *$ & 0.74 \\
\hline
\end{tabular}

Level of significance: ${ }^{* *}<1 \% ; m=$ mean; se $=$ standard error; $n=$ number of independent estimations; $R=$ ratio of $h^{2}$ over $t$. A non-parametric test (Mann-Whitney $U$-test) was used for the comparisons of mean values of $h^{2}$ and $t$.

\section{Apportionment of total variability in the 2 species}

It seemed interesting to consider the results of this paper together with those of Capy et al (1993) in order to get an overall view of the apportionment of the variability in each species. Table VII gives the proportion of the total variability explained at the 4 levels considered in the analyses.

Table VII. Apportionment of the total variability in the 2 sibling species calculated from all the available populations ( 55 for $D$ melanogaster and 25 for $D$ simulans) ${ }^{*}$.

\begin{tabular}{lcrrrrrrrr}
\hline Source of variation & Species & \multicolumn{1}{c}{$\mathrm{n}$} & $F W$ & $T L$ & $W L$ & \multicolumn{1}{c}{$A B$} & \multicolumn{1}{c}{$S B$} & ON & Average \\
\hline Within-line & D mel & 6160 & 13.69 & 34.98 & 10.35 & 48.01 & 57.05 & 39.04 & 33.85 \\
& D sim & 2210 & 24.34 & 63.77 & 42.89 & 58.78 & 73.19 & 66.44 & 54.90 \\
Between-line & D mel & 616 & 17.98 & 11.05 & 7.59 & 20.53 & 26.79 & 15.07 & 16.50 \\
Within-population & D sim & 221 & 33.30 & 14.47 & 32.79 & 28.18 & 20.53 & 10.60 & 23.30 \\
Between-population & D mel & 49 & 14.49 & 16.19 & 20.93 & 10.86 & 4.50 & 28.72 & 15.95 \\
Within-region & D sim & 24 & 30.12 & 15.63 & 19.07 & 1.75 & 6.04 & 12.62 & 14.20 \\
Between-region & D mel & 10 & 53.84 & 37.78 & 61.13 & 20.60 & 11.66 & 17.17 & 33.70 \\
& D sim & 8 & 12.24 & 6.13 & 5.23 & 11.29 & 0.24 & 10.34 & 7.60 \\
\hline
\end{tabular}

* The data used to build this table are from Capy et al (1993) and from the present analysis. The values given in this table are the percentage of the total variability. D mel $=D$ melanogaster $; \mathrm{D}$ sim $=D$ simulans $; \mathrm{FW}=$ fresh weight $; \mathrm{AB}=$ abdominal bristle number; $\mathrm{SB}=$ sternopleural bristle number; $\mathrm{TL}=$ thorax length $; \mathrm{WL}=$ wing length $;$ and $\mathrm{ON}=$ ovariole number; $n=$ number of items, ie individuals, isofemale lines, populations and regions. 
If we consider the average values for the 6 traits, we see that the proportion of the within-isofemale line variability is much larger in $D$ simulans than in $D$ melanogaster (55 versus $34 \%$ ) while the reverse situation is found for the longrange variation between regions ( $34 \%$ in $D$ melanogaster against $8 \%$ in $D$ simulans). This again illustrates the fact that $D$ melanogaster is much more diversified into geographic races (see Capy et al, 1993). If we consider variations between isofemale lines from the same population or between populations of the same region, the 2 species are quite similar. Besides the general trend outlined above, differences exist between traits. For example, if we consider the 3 size-related traits, the variations between regions explain $51 \%$ of the total variance in $D$ melanogaster, but only $8 \%$ in $D$ simulans. Thus, the contrast between the 2 species is more pronounced for these traits. For bristle numbers, most of the variation is harbored within local populations, ie $90 \%$ in $D$ simulans and $76 \%$ in $D$ melanogaster at the 2 first levels. Finally, for the ovarioles number, variations are more evenly distributed.

\section{Is $\mathrm{D}$ melanogaster more variable than $\mathrm{D}$ simulans?}

The analysis of the between-population variability of many traits has shown that the geographical divergence of $D$ melanogaster is higher than that of $D$ simulans However, the within- and the between-components of the total variance must be considered together. Indeed, while the 2 species have similar amount of variability at the within-population level, they greatly differ at the between-population level. This observation is in agreement with several analyses dealing with other traits (Hyytia et al, 1985; Inoue and Yamamoto, 1987; Singh et al, 1987; Capy et al, 1993). Moreover, in few cases, $D$ simulans appears to be more variable than $D$ melanogaster (Kawanishi and Watanabe, 1981; Aquadro et al, 1988; Begun and Aquadro, 1991).

How can we explain these differences of variability at the between- and withinpopulation levels? Two of the hypotheses (summarized in Capy et al, 1993) proposed to interpret the geographical differences between $D$ melanogaster and $D$ simulans, based on migration rates $(m)$ and on effective population sizes $\left(N_{e}\right)$, could explain such a phenomenon.

Under the migration-rate hypothesis, proposed from the analysis of enzymatic polymorphism (Choudhary and Singh, 1987), it is assumed that this rate should be 2-4-fold times lower in $D$ melanogaster. On the other hand, under the effective population size hypothesis, based on a lower level of nucleotidic variation in $D$ melanogaster, it is suggested that $N_{e}$ of $D$ simulans should be 6 -fold higher than that of $D$ melanogaster thus leading to an increased purifying selection (Aquadro et al, 1988).

These 2 hypotheses assume that the mutation rate is similar in the 2 species. However, several reports, including those of Dowsett and Young (1982) and Lemeunier and Aulard (1993), suggest that this rate could be lower in $D$ simulans.

In conclusion, it seems that the different hypotheses are plausible and not mutually exclusive. But due to a lack of ecological and genetic information, it is not possible to choose between them and/or to determine their relative impact on the variability of the 2 species. Moreover a general comparison of these 2 species, including data from molecule to ecology and to biogeography, will be necessary to try to understand how these 2 species, which share a recent common ancestor, have accumulated such differences. 


\section{ACKNOWLEDGMENTS}

We thank the numerous people who helped us by providing samples of natural populations. This work has benefited from a PIREN (French CNRS) grant.

\section{REFERENCES}

Aquadro CF, Lado KM, Noon WA (1988) The rosy region of Drosophila melanogaster and Drosophila simulans. I. Contrasting levels of naturally occurring DNA restriction map variation and divergence. Genetics $119,875-888$

Begun DJ, Aquadro CF (1991) Molecular population genetics of the distal portion of the $\mathrm{X}$ chromosome in Drosophila: evidence for genetic hitchhiking of the yellowachaete region. Genetics 129, 1147-1158

Bouletreau-Merle J, Allemand R, Cohet Y, David JR (1982) Reproductive strategy in Drosophila melanogaster: significance of a genetic divergence between temperate and tropical populations. Oecologia (Berl) 53, 323-329

Brotherstone S, Hill WG (1986) Heterogeneity of variance amongst herds for milk production. Anim Prod 42, 297-303

Bulmer MG (1985) The Mathematical Theory of Quantitative Genetics. Clarendon Press, Oxford

Capy P (1987) Variabilité génétique des populations naturelles de Drosophila melanogaster et Drosophila simulans. Thèse Université de Paris XI, Orsay.

Capy P, Pla E, David JR (1993) Phenotypic and genetic variability of morphometrical traits in natural populations of Drosophila melanogaster and $D$ simulans. I. Geographic variations. Genet Sel Evol 25, 517-536

Choudhary M, Singh RS (1987) A comprehensive study of genic variation in natural populations of Drosophila melanogaster. III Variations in genetic structure and their causes between Drosophila melanogaster and Drosophila simulans. Genetics 117, 697-710

David JR (1979) Utilization of morphological traits for the analysis of genetic variability in wild populations. Aquilo Ser Zool 20, 49-61

David JR, Bocquet C, de Scheemaeker-Louis M, Pla E (1978) Utilisation du coefficient de variation pour l'analyse de la variabilité de caractères quantitatifs chez Drosophila melanogaster: comparaison de souches appartenant à trois races géographiques. Arch Zool Exp Gen 118, 481-494

David JR, Cohet Y, Fouillet P, Arens MF (1980) Phenotypic variability of wild collected Drosophila: an approach toward understanding selective pressures in natural populations. Egypt J Genet Cytol 9, 51-66

David JR, Allemand R, Van Herrewege J, Cohet Y (1983) Ecophysiology: abiotic factors. In: The Genetics and Biology of Drosophila (M Ashburner, HL Carsons, JN Thompson Jr, eds). Acad Press, London Vol 3d, 105-170

Dowsett AP, Young MW (1982) Differing levels of dispersed repetitive DNA among closely related species of Drosophila. Proc Natl Acad Sci USA 79, 4570-4574

Falconer DS (1981) Introduction to Quantitative Genetics. Longman, London Fisher RA (1930) The Genetical Theory of Natural Selection. Clarendon Press Oxford 
Hoffmann AA, Parson PA (1988) The analysis of quantitative variation in natural populations with isofemale strains. Genet Sel Evol 20, 87-98

Hyytia P, Capy P, David JR, Singh RS (1985) Enzymatic and quantitative variation in European and African populations of Drosophila simulans. Heredity 54, 209-217 Inoue YH, Yamamoto MT (1987) Insertional DNA and spontaneous mutation at the white locus in Drosophila simulans. Mol Gen Genet 209, 94-100

Jaspen N (1965) The calculation of probabilities corresponding to values of $z, t, F$ and chi-square. Educ Psychol Measur 25, 877-880

Kawanishi M, Watanabe TK (1981) Genes affecting courtship song and mating preference in Drosophila melanogaster, Drosophila simulans and their hybrids. Evolution 35, 1128-1133

Lemeunier F, Aulard S (1993) Inversion polymorphism in Drosophila melanogaster. In: Drosophila Inversion Polymorphism (CB Krimbas, JR Powell eds). CRC Press, London, 339-405

Lerner IM (1954) Genetic Homeostasis. John Wiley, New York

Levene $\mathrm{H}$ (1960) Robust tests for equality of variances. In: Contributions to Probability and Statistics (I Olkin, ed) Stanford Univ Press, 278-292

Lewontin RC (1974) The Genetic Basis of Evolutionary Change. Columbia Univ Press

Parson PA (1983) The Evolutionary Biology of Colonizing Species. Camb Univ Press Roff DA, Mousseau TA (1987) Quantitative genetics and fitness: lessons from Drosophila. Heredity 58, 103-118

Shrimpton A, Robertson A (1988) The isolation of polygenic factors controlling bristle score in Drosophila melanogaster. II. Distribution of the third chromosome bristle effects within chromosome sections. Genetics 118, 445-459

Singh RS, Choudhary M, David JR (1987) Contrasting patterns of geographic variation in the cosmopolitan sibling species Drosophila melanogaster and $D$ simulans. Biochem Genet 25, 27-40

Suh DS, Mukai T (1991) The genetic structure of natural populations of Drosophila melanogaster. XXIV. Effects of hybrid dysgenesis on the components of genetic variance of viability. Genetics $127,545-552$

Thoday JM (1961) The location of polygene. Nature 191, 368-370

Thompson Jr JN (1975) Quantitative variation and gene number. Nature 258, 665668 